\title{
Dextrocardia in patients with Poland syndrome: Phenotypic characterization provides insight into the pathogenesis
}

\author{
Michele Torre, MD, ${ }^{\mathrm{a}, *}$ Anwar Baban, MD, ${ }^{\mathrm{b}, \mathrm{c}, *}$ Anna Buluggiu, MD, ${ }^{\mathrm{a}}$ Sara Costanzo, ${ }^{\mathrm{a}}$ Lara Bricco, MD, ${ }^{\mathrm{b}}$ \\ Margherita Lerone, MD, ${ }^{b}$ Sebastiano Bianca, MD, ${ }^{\mathrm{d}}$ Gian Luca Gatti, MD, ${ }^{\mathrm{e}}$ Filippo Maria Sénès, MD, \\ Maura Valle, MD, ${ }^{\mathrm{g}}$ and Maria Grazia Calevo, $\mathrm{PhD}^{\mathrm{h}}$
}

Objective: Poland syndrome is a rare congenital anomaly characterized by complete or partial agenesis of the pectoralis major muscle variably associated with other thoracic malformations, upper limb malformations, or both. More than 20 patients with dextrocardia and left-sided Poland syndrome have been previously described. The association between these 2 rare anomalies suggests a causal relationship, but the etiopathogenetic mechanism has not been clarified yet. We studied the clinical correlation between these 2 anomalies, and we tried to elucidate whether dextrocardia or Poland syndrome comes first.

Methods: This is a multicentric multidisciplinary study conducted over the last 5 years. We identified 122 patients with Poland syndrome, and we investigated heart position through different imaging techniques. Logistic regression statistical analyses were carried out.

Results: We observed dextrocardia in $14(11.5 \%)$ patients, which was never associated with situs inversus. All of them presented with left-sided Poland syndrome and partial agenesis of 2 or more ribs. Conversely, all patients with Poland syndrome with partial agenesis of 2 or more ribs presented with dextrocardia, whereas dextrocardia was never associated with partial agenesis of a single rib. Three patients with dextrocardia presented with simple congenital heart defects.

Conclusions: These findings suggest that mechanical factors during embryonic life could explain the strong association between left-sided Poland syndrome and dextrocardia. According to this hypothesis, partial agenesis of 2 or more ribs is needed to displace the heart toward the right side. The peculiar features of dextrocardia when associated with Poland syndrome (neither associated with situs inversus nor complex intracardiac anomalies) support our hypothesis. (J Thorac Cardiovasc Surg 2010;139:1177-82)

In 1841, Alfred Poland was one of the first who described the association of ipsilateral pectoral muscle defect and hand syndactyly. ${ }^{1}$ Since that time, numerous reports further described this association, which has become known as Poland syndrome (PS).

PS is a rare congenital anomaly characterized by agenesis or hypoplasia of the pectoralis major and minor muscles. In most cases pectoral involvement is associated with a wide spectrum of thoracic and upper limb deformities, such as hypoplasia or absence of the breast or nipple, agenesis or deformity of ribs, and ipsilateral hand deformities. According to

\footnotetext{
From the Pediatric Surgery Department, ${ }^{\text {a }}$ the Laboratory of Molecular Genetics, ${ }^{\mathrm{b}}$ the Cardiovascular Department, ${ }^{\mathrm{c}}$ the Hand Surgery and Microsurgery Unit, ${ }^{\mathrm{f}}$ the Radiology Unit, ${ }^{\mathrm{g}}$ and the Epidemiology and Biostatistics Service, Scientific Direction, ${ }^{\mathrm{h}}$ Gaslini Children Hospital, Genova, Italy; the Reproductive Genetic Counselling and Teratology Center, ${ }^{\mathrm{d}}$ Maternal and Infant Department, ARNAS Garibaldi Nesima, Catania, Italy; and the Plastic and Reconstructive Surgery and Burn Centre Unit, ${ }^{\mathrm{e}}$ Hospital of Pisa, Pisa, Italy.

Disclosures: None.

* M. Torre and A. Baban contributed equally to this work.

Received for publication March 31, 2009; revisions received July 19, 2009; accepted for publication Aug 10, 2009; available ahead of print Nov 12, 2009.

Address for reprints: Michele Torre, MD, Pediatric Surgery Department, Gaslini Children Hospital, Largo G. Gaslini 5, 16148 Genova-Italy (E-mail: micheletorre@ hotmail.com).

$0022-5223 / \$ 36.00$

Copyright (C) 2010 by The American Association for Thoracic Surgery

doi:10.1016/j.jtcvs.2009.08.024
}

different authors, the incidence of PS is $1: 20,000$ to $1: 30,000$ live births. ${ }^{2,3}$

Dextrocardia is an embryologic malformation characterized by the displacement of the major axis (base to apex) of the heart to the right side of the chest, with reversion of the apical inclination (Figure 1). The association of PS and dextrocardia has been reported in 22 cases until now, ${ }^{4-11}$ accounting for $5.6 \%$ of reported PS cases. ${ }^{5}$ This is an exceedingly high association rate that suggests a causal relationship between these 2 rare anomalies, but it is not clear yet whether PS or dextrocardia comes first. ${ }^{5}$ Both explanations are possible: dextrocardia occurs first and consequential vascular anomalies determine PS, or some factor in fetuses with PS determines secondary dextrocardia. Finally, a third possibility is that the same causal factor leading to dextrocardia is able to determine an alteration in the thoracic development, finally resulting in PS.

In this study we investigated the clinical correlation between PS and dextrocardia, suggesting a possible etiopathogenetic explanation of this association.

\section{MATERIALS AND METHODS}

Over a 5-year period (January 2003 to December 2008), 122 patients with PS were referred to 3 medical centers that were members of the Scientific Committee of the Italian Association of Poland Syndrome. More than $90 \%$ of them were evaluated in a single Center (G. Gaslini Institute, 


\section{Abbreviations and Acronyms \\ $\mathrm{CI}=$ confidence interval \\ $\mathrm{OR}=$ odds ratio \\ $\mathrm{RH}=$ rib hypoplasia \\ $\mathrm{PRA}=$ partial rib agenesis \\ $\mathrm{PS}=$ Poland syndrome}

Genova, Italy). The diagnosis of PS was made if complete or partial agenesis of the pectoralis major muscle was clinically observed and confirmed by means of ultrasonographic examination. All the patients underwent clinical and radiologic examinations to rule out other thoracic anomalies, upper limb anomalies, or both, as well as other associated anomalies. Our protocol for patients with PS includes pectoral region ultrasonographic, thoracic radiographic, echocardiographic, and abdominal ultrasonographic analysis. Some patients with specific indications undergo hand or spine radiographic analysis or thoracic computed tomographic analysis.

Heart position was determined in all individuals by means of chest (103 patients), spine (25 patients), or both radiographic analysis and/or echocardiographic analysis (96 patients). Computed tomographic scanning or magnetic resonance imaging was performed in 21 patients for specific indications.

We defined partial rib agenesis (PRA) as the lack of the anterior costal arc, with the rib ending without joining the sternum (Figure 2, $A$ ). We defined rib hypoplasia $(\mathrm{RH})$ as the anomaly of a rib (thinner or deformed) normally articulating with the sternum (Figure 2, $B$ ). ${ }^{12}$

Informed consent, according to the guidelines approved by our ethics committee, was obtained from adult patients and from the parents or legal guardians of every child participating in the study.

Data were described as means, standard deviations, and medians with range for continuous variables, whereas absolute and relative frequencies were used for categorical variables. Univariate analysis was carried out to determine the potential risk factors significantly associated with left-sided PS.

Logistic regression analyses were used for each variable, and results are reported as odds ratios (ORs) with $95 \%$ confidence intervals (CIs). For each analysis, the absence of exposure to the factor or the variable less likely associated with the risk was used as the reference.

All $P$ values were based on 2-tailed tests. Statistical analysis was performed with SPSS for Windows (SPSS, Inc, Chicago, Ill).

\section{RESULTS}

One hundred twenty-two patients with PS were studied. Their age ranged from 6 months to 53 years, with a median age of 8.9 years. Median age at diagnosis was 3 months (range, birth to 43 years); $57 \%$ of them were given diagnoses during the first year of the life. As shown in Table 1, PS was more frequently observed in male subjects $(68 \%)$ than in female subjects $(32 \%)$, with a 2:1 ratio, and more frequently on the right side $(59 \%)$ than on the left side $(41 \%)$. Fifty-seven $(81.4 \%)$ of the 72 patients with rightsided PS had normal ribs, and $13(18.6 \%)$ had rib defects, whereas $30(60 \%)$ of the 50 patients with left-sided PS had normal ribs, and $20(40 \%)$ had rib defects: $3(6 \%)$ with $\mathrm{RH}$ and $17(34 \%)$ with PRA. Univariate analysis showed that left-sided PS was strongly associated with PRA (OR, 4.61; 95\% CI, 1.72-12.35; $P=.009$; Table 1).

Dextrocardia was observed in $14(11.5 \%)$ patients. The clinical features of these patients are summarized in Table 2.

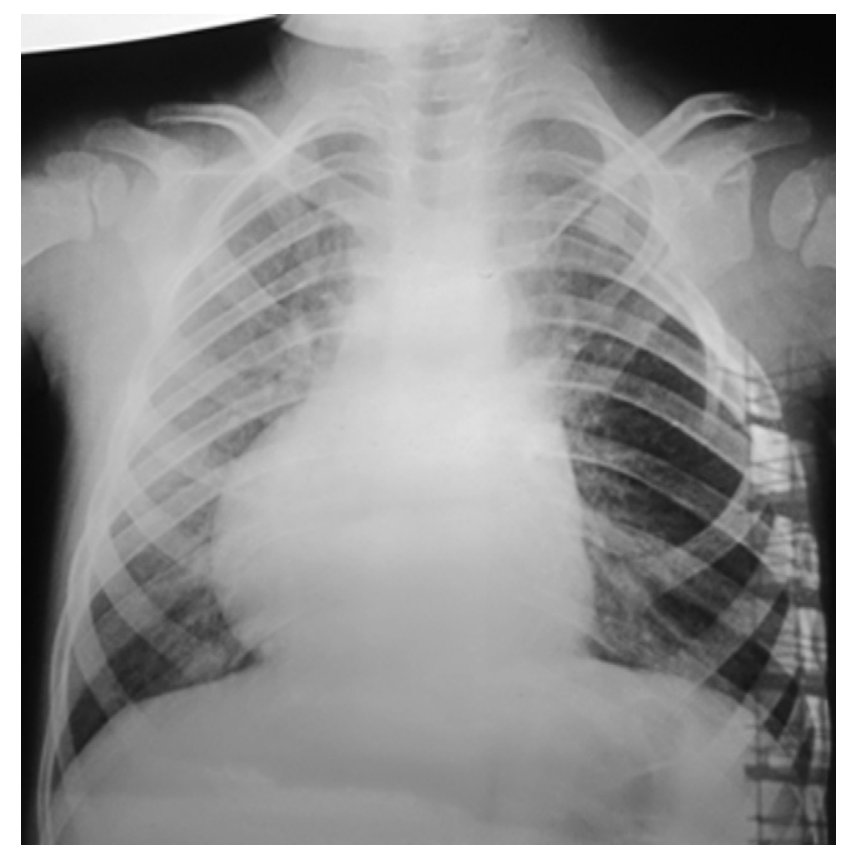

FIGURE 1. Thoracic radiograph showing dextrocardia and partial rib agenesis of the third and fourth left ribs.

In these patients we observed the same male/female ratio (2:1) as in our PS population. Univariate analysis showed that left-sided PS was strongly associated with isolated dextrocardia (OR, 57; 95\% CI, 3.3 to very high; $P=.00001)$. Simple congenital heart defects were observed in 3 patients with dextrocardia (2 patients with an atrial septal defect that closed spontaneously in one of them and 1 patient with a ventricular septal defect). Nine patients had normal upper limbs, 2 presented mild hypoplasia, only 2 showed the classic symbrachydactyly, and 1 had absent fingers and Sprengel anomaly.

All 14 patients with dextrocardia presented with left-sided PS with PRA. Considering the number of cases of PRA, all patients with dextrocardia had PRA of 2 or more ribs, affecting more frequently the second, third, and fourth ribs, whereas PRA of a single rib was never associated with dextrocardia (Table 3). On the other hand, all patients with PRA of 2 or more ribs presented with dextrocardia.

No specific constant exposure to environmental factors during pregnancy was observed in these patients. All 14 patients with PS had sporadic disease. However, a positive family history for dextrocardia was present in patient 5, whose paternal aunt presented with dextrocardia. Detailed information regarding this relative was not available. Patient 13's mother showed postural scoliosis, and the father had mild scapular asymmetry (higher left scapula).

\section{DISCUSSION}

Clinical manifestations of PS are extremely variable, and rarely are all the recognized features present in 1 patient. The 


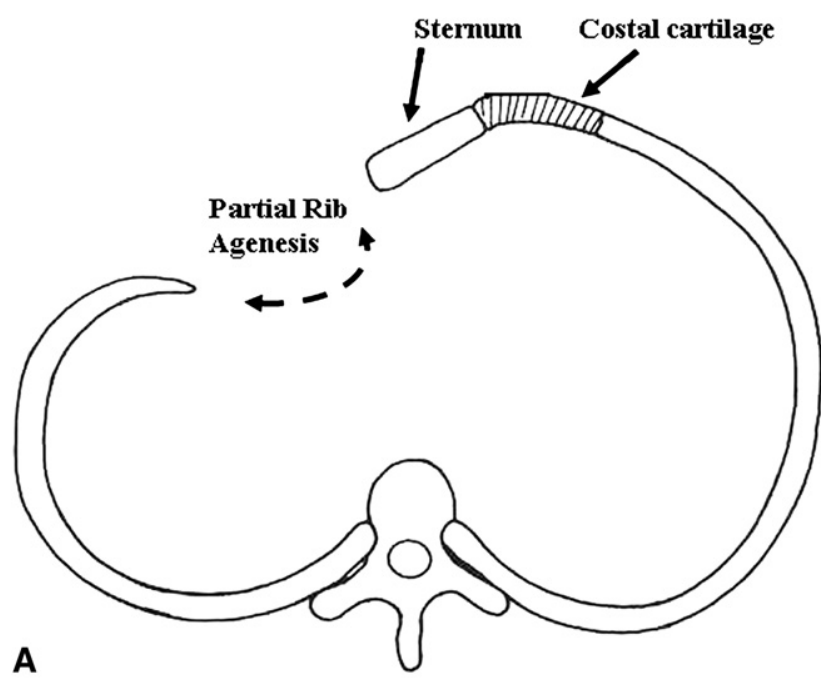

A

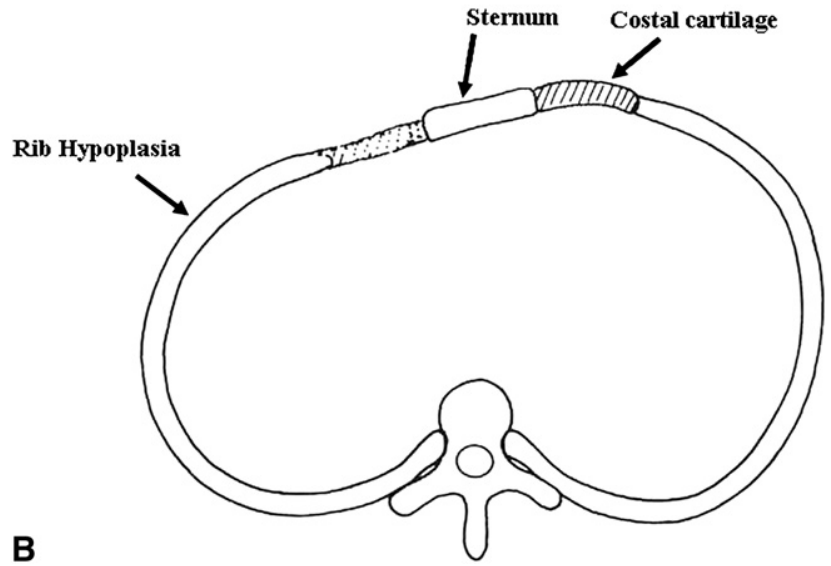

FIGURE 2. Schematic representation of rib defects in patients with Poland syndrome: partial rib agenesis (A) and rib hypoplasia (B).

syndrome is more common in male than in female subjects and is more prevalent on the right side than on the left side. ${ }^{2,3}$ The most common variation is the absence of the sternocostal head of the pectoralis major muscle, with con- comitant hypertrophy of the clavicular head and absence of the pectoralis minor. In some cases, other associated anomalies, such as dextrocardia, vertebral defects, renal aplasia or hypoplasia, and lower limb anomalies, have been described. ${ }^{13-15}$ PS can be associated with other known syndromes in the same patient, such as PS and Moebius syndrome, ${ }^{16,17} \mathrm{PS}$ and facioauriculovertebral dysplasia, ${ }^{18}$ and PS and frontonasal dysplasia. ${ }^{19}$ Although most described cases are sporadic, rare familial instances of PS have also been observed. ${ }^{20}$

Different possible causes of PS can be taken into consideration, in particular genetic factors (multifactorial or single gene defect) and teratogenic agents (maternal exposure to drugs, smoking, and others). The most frequently mentioned etiologic theory is the vascular one, according to which an insult during the sixth week of gestation might be responsible for anomalies of the pectoralis major muscle and hand syndactyly. Bavinck and Weaver ${ }^{13}$ proposed the term "subclavian artery supply disruption sequence," suggesting a common pathogenesis for PS, Klipple-Feil syndrome, and Moebius syndrome; isolated terminal transverse limb defects; and Sprengel (high scapula) anomaly. According to this hypothesis, interruption of the embryonic blood supply in the subclavian or vertebral arteries produces these variable defects depending on where the restriction of blood flow occurs. Paradominant inheritance was suggested as a possible mechanism for PS. ${ }^{21}$ Another proposed concept for PS and several other syndromes is the presence of an autosomal lethal gene surviving by means of mosaicism. ${ }^{22}$

Dextrocardia is a type of cardiac malposition characterized by the presence of a cardiac mass in the right hemithorax. The literature presents a great diversity of types of dextrocardia, with difficulty in underlying precise classifications. Classical dextrocardia is usually caused by an anomalous rotation of the primitive heart tube to the left in which the bulboventricular loop bends to the left in a specular image of the normal condition. Dextrocardia can be part of situs

TABLE 1. Univariate analysis of clinical characteristics of patients with Poland syndrome

\begin{tabular}{|c|c|c|c|c|c|}
\hline & Right side $(n=72)$, no. $(\%)$ & Left side $(n=50)$, no. $(\%)$ & OR & $\mathbf{9 5} \% \mathrm{CI}$ & $P$ value \\
\hline \multicolumn{6}{|l|}{ Sex } \\
\hline Female & 22 (30.6) & $17(34)$ & Reference & & \\
\hline Male & $50(69.4)$ & $33(66)$ & 0.88 & $0.40-1.92$ & .75 \\
\hline \multicolumn{6}{|l|}{ Ribs } \\
\hline Normal & $57(81.4)^{*}$ & $30(60)$ & Reference & & \\
\hline Hypoplasia & $6(8.6)$ & $3(6)$ & 0.95 & $0.22-4.07$ & \\
\hline Partial agenesis & $7(10)$ & $17(34)$ & 4.61 & $1.72-12.35$ & .009 \\
\hline 1 rib & 0 & 3 & & & \\
\hline$\geq 2$ ribs & 7 & 14 & & & \\
\hline \multicolumn{6}{|l|}{ Dextrocardia } \\
\hline No & $72(100)$ & $36(72)$ & Reference & & \\
\hline Yes & - & $14(28)$ & 57 & $3.3-\mathrm{VH}$ & .00001 \\
\hline
\end{tabular}

$O R$, Odds ratio; $95 \% C I, 95 \%$ confidence interval; $V H$, very high. *Two missing data. 
TABLE 2. Clinical features of patients with Poland syndrome with dextrocardia

\begin{tabular}{|c|c|c|c|c|c|c|c|c|c|c|}
\hline $\begin{array}{l}\text { Patient } \\
\text { no. } \\
\end{array}$ & Sex & $\begin{array}{l}\text { Affected } \\
\text { side }\end{array}$ & $\begin{array}{c}\text { Pectoralis } \\
\text { major } \\
\text { (ultrasound) }\end{array}$ & $\begin{array}{c}\text { Pectoralis } \\
\text { minor } \\
\text { (ultrasound) }\end{array}$ & $\begin{array}{c}\text { Affected } \\
\text { ribs }\end{array}$ & Nipple & $\begin{array}{l}\text { Upper } \\
\text { limb }\end{array}$ & $\begin{array}{l}\text { Cardiac } \\
\text { defects }\end{array}$ & $\begin{array}{c}\text { Other } \\
\text { malformations }\end{array}$ & $\begin{array}{c}\text { Sporadic/familial } \\
\text { occurrence }\end{array}$ \\
\hline 1 & $\mathrm{~F}$ & $\mathrm{~L}$ & $\mathrm{H}$ & A & PRA 3rd, 4th & $\mathrm{H}$ & $\mathrm{BS}+$ & No & No & $S$ \\
\hline 2 & M & $\mathrm{L}$ & NA & NA & $\begin{array}{l}\text { PRA 3rd, 4th } \\
\text { H2nd, 5th }\end{array}$ & $\mathrm{H}$ & NR & No & No & $S$ \\
\hline 3 & M & $\mathrm{L}$ & $\mathrm{H}$ & A & PRA 3rd, 4th, 5th & $\mathrm{H}$ & NR & $?$ & $\begin{array}{l}\text { Right undescended } \\
\text { testis, splenomegaly }\end{array}$ & $S$ \\
\hline 4 & M & $\mathrm{L}$ & A & NA & PRA 2nd, 3rd & $\mathrm{H}$ & $\mathrm{H}$ & No & No & $\mathrm{S}$ \\
\hline 5 & M & $\mathrm{L}$ & A & A & PRA 3rd, 4th & NR & NR & No & $\begin{array}{l}\text { IHBD and } \\
\text { hypertelorism }\end{array}$ & $\begin{array}{l}\text { Paternal } \\
\text { grandaunt with } \\
\text { dextrocardia }\end{array}$ \\
\hline 6 & M & $\mathrm{L}$ & $\mathrm{A}$ & A & PRA 3rd, 4th & $\mathrm{H}$ & $\mathrm{H}$ & No & No & $\mathrm{S}$ \\
\hline 7 & M & $\mathrm{L}$ & NA & NA & PRA 3rd, 4th, 5th & $\mathrm{H}$ & NR & No & $\begin{array}{c}\text { No; asymmetric } \\
\text { mixed sternal } \\
\text { abnormality }\end{array}$ & $S$ \\
\hline 8 & M & $\mathrm{L}$ & A & A & PRA 4th, 5th, 6th & $\mathrm{H}$ & NR & ASD-SC & No & $\mathrm{S}$ \\
\hline 9 & $\mathrm{~F}$ & $\mathrm{~L}$ & $\mathrm{H}$ & A & $\begin{array}{c}\text { PRA 2nd, 3rd; } \\
\text { H 1st, 4th }\end{array}$ & NR & NR & No & $\begin{array}{l}\text { Convergent squint, } \\
\text { astigmatism, } \\
\text { hypermetropia }\end{array}$ & $S$ \\
\hline 10 & $\mathrm{~F}$ & $\mathrm{~L}$ & $\mathrm{H}$ & A & PRA 2-3-4 & $\mathrm{H}$ & NR & No & $\begin{array}{l}\text { No asymmetric } \\
\text { pectus carinatum }\end{array}$ & $\mathrm{S}$ \\
\hline 11 & $\mathrm{~F}$ & $\mathrm{~L}$ & A & A & PRA 3rd, 4th & $\mathrm{H}$ & NR & No & No & $S$ \\
\hline 12 & M & $\mathrm{L}$ & A & NR & PRA 3rd, 4th & $\mathrm{H}$ & $\mathrm{AF}+\mathrm{SA}$ & No & $\begin{array}{c}\text { Salivary } \operatorname{IgA} \text { deficiency } \\
\text { asymmetric mixed } \\
\text { sternal abnormality }\end{array}$ & $S$ \\
\hline 13 & M & $\mathrm{L}$ & A & NA & PRA 2nd, 3rd & $\mathrm{H}$ & BS+ & ASD & $\begin{array}{l}\text { Sylvian duct } \\
\text { stenosis of } \\
\text { malformative origin }\end{array}$ & $\begin{array}{l}\text { Mother: postural } \\
\text { scoliosis; Father: } \\
\text { mild scapular } \\
\text { asymmetry (higher } \\
\text { left scapula) }\end{array}$ \\
\hline 14 & $\mathrm{~F}$ & $\mathrm{~L}$ & A & A & PRA 4th, 5th & $\mathrm{H}$ & NR & VSD & $\begin{array}{l}\text { Small congenital } \\
\text { occipital vascular } \\
\text { anomaly, vertebral } \\
\text { schisis C7-T5 }\end{array}$ & $\mathrm{S}$ \\
\hline
\end{tabular}

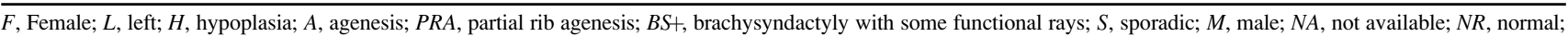
$I H B D$, intrahepatic biliary duct dilatation; $A S D$, atrial septal defect; $S C$, spontaneous closure; $A F$, absent fingers; $S A$, Sprengel anomaly; $V S D$, ventricular septal defect.

inversus (transposition of the viscera, such as the liver being on the left side and the heart on the right side), with an estimated incidence of 1:10,000. The incidence of accompanying cardiac defects in this form is relatively low. The incidence of dextrocardia with situs solitus (the abnormal position of the heart is not accompanied by displacement of other viscera), which is also called isolated dextrocardia, is 1:30,000 live births and only 1:900,000 in the adult population. This incidence discrepancy is due to the higher percentage of associated cardiac diseases, extracardiac diseases, or both leading to increased mortality. ${ }^{23,24}$

Most authors call dextroposition the condition in which the heart is on the right side because of factors that either reduce the volume of the right lung or occupy space in the left thoracic cavity. In this condition, as opposed to primary dextrocardia, the apex lies on the left side, and cardiac anomalies are much less common. The term dextroversion describes another condition resulting from rotational abnormalities of the cardiac loop during development. ${ }^{5}$

The combination of PS and isolated dextrocardia has seldom been described. To date, 22 cases have been published. ${ }^{4-11}$ In all of them (when the description was available), PS was left sided and associated with rib defects. In only 1 case were PS and dextrocardia associated with abdominal heterotaxia. ${ }^{4}$

To the best of our knowledge, the present study is based on the largest case series of patients with PS. Based on our 14 cases of PS with dextrocardia, we can confirm that dextrocardia can be considered a component of a specific form of this syndrome (ie, left-sided PS with rib defects). Indeed, in our series the frequency of the association between PS and dextrocardia $(>11.5 \%)$ was higher than that previously reported by Fraser and colleagues 5 (5.6\%), which suggests that dextrocardia's incidence in PS is probably 
TABLE 3. Left-sided Poland syndrome with PRA

\begin{tabular}{lcc}
\hline & Levocardia & Dextrocardia \\
\hline Affected ribs & No. of cases & No. of cases \\
2nd, 3rd & - & 3 \\
2nd, 3rd, 4th & - & 1 \\
3rd & 3 & - \\
3rd, 4th & - & 6 \\
3rd, 4th, 5th & - & 2 \\
4th, 5th & - & 1 \\
4th, 5th, 6th & - & 1 \\
Total & 3 & 14
\end{tabular}

All 3 patients with partial rib agenesis of a single rib (always to the third rib) presented with levocardia. All 14 patients with partial rib agenesis of 2 or more ribs presented with dextrocardia. PRA, Partial rib agenesis.

underestimated. The most interesting finding of our study is the high incidence of left-sided PS with rib defects presenting with dextrocardia $(14 / 20[70 \%])$ and the correlation between the type of rib anomaly and dextrocardia. In fact, we found that dextrocardia was always associated with leftsided PRA and never with left-sided RH. Considering PRA, the higher the number of ribs involved, the higher the risk of dextrocardia. This observation seems to suggest that dextrocardia in patients with PS can be caused by intrauterine mechanical factors pushing a normal heart toward the right side, as Fraser and colleagues ${ }^{5}$ first suspected some years ago and other authors proposed again later. ${ }^{10} \mathrm{Ac}-$ cording to this hypothesis (Figure 3), if only a single leftsided PRA exists $(3 / 3[100 \%]$ in our series), the pressure is probably not high enough to displace the heart, whereas if left-sided PRA of 2 or more ribs is present (14/14 [100\%] in our series), dextrocardia always occurs. This mechanical etiopathogenetic hypothesis might explain why the incidence of intracardiac defects in dextrocardia associated with PS (3/15 in our series) is lower than usually observed in patients with situs solitus dextrocardia, in whom congenital heart defects are almost always $(96 \%)$ associated. ${ }^{25}$ On the other hand, the presence of 3 patients with congenital heart defects in our series, with a ventricular septal defect in 1 and atrial septal defects in 2 , represents a higher percentage than expected if we consider that dextrocardia is secondary to merely mechanical factors (ie, dextroposition). If we speculate the presence of such a higher percentage of heart anomalies in this category, we might think more toward giving accreditation to the hypothesis that dextrocardia is part of the PS spectrum and that it arises before any subsequent mechanical factor. However, the absence of any classically associated complex cardiac and extracardiac abnormalities in this series might weaken the primary isolated dextrocardia and strengthen the possibility of mechanical forces leading to dextroposition.

If the mechanical hypothesis is correct, dextrocardia in patients with PS could be actually considered a dextroposition, and the left rib agenesis associated with muscular defects is the causative factor. The displacement of the heart probably occurs during pregnancy, as in the case reported by Sepulveda, ${ }^{11}$ in which an ultrasonographic study at the 31 st week of gestation demonstrated dextrocardia in a fetus with postnatal diagnosis of left-sided PS and PRA of multiple ribs. On the same fetus, a previous ultrasonographic scan at the 21st week did not show heart position anomalies.

Regarding PS treatment, our findings (dextrocardia always associated with left-sided PS with PRA of 2 or more ribs) could influence the treatment of this variant. For example, one can speculate that dextrocardia could be a protective factor for the heart against traumatic events. The indication for a protective thoracoplasty during infancy or childhood

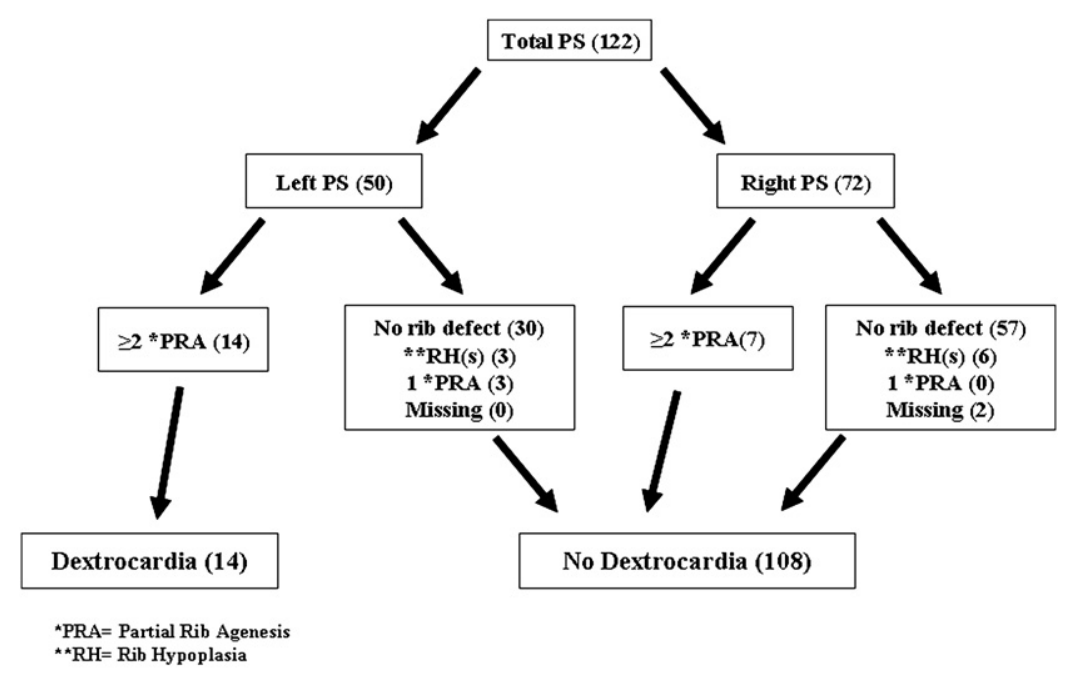

FIGURE 3. Our hypothesis to explain dextrocardia in patients with Poland syndrome (PS). Dextrocardia occurs always in patients with left-sided PS with partial rib agenesis (PRA) of 2 or more ribs. Dextrocardia never occurs in patients with right-sided PS or in patients with left-sided PS without rib defects or with rib hypoplasia $(R H)$ or PRA of a single rib. 
in these patients is a matter of debate; however, the treatment of PS is not the topic of our article, and other studies are necessary to elucidate these aspects.

In conclusion, our study confirms that left-sided PS can be associated with dextrocardia but more frequently than previously reported. This article addresses that dextrocardia is a component of left-sided PS with PRA of 2 or more ribs. Our data seem to confirm the hypothesis that dextrocardia derives from a mechanical intrauterine displacement of a healthy heart toward the right side because of a lack of protection by the thoracic cage against external pressures. Further studies are required to confirm this hypothesis.

We thank the patients and their families. In particular, we are grateful to the "Associazione Italiana Sindrome di Poland ONLUS", (AISP) for their fundamental help and enthusiastic support to our work. We thank the physicians who collaborated in creating this multidisciplinary management of patients with PS: Professor Jasonni, Professor Ravazzolo, Dr Catena, Dr Divizia, Dr Garavelli, Dr Martinoli, Dr Morelli, and Dr Zarri. Finally, we thank Anna Capurro for language revision.

\section{References}

1. Poland A. Deficiency of the pectoral muscles. Guy Hosp Rep. 1841;6:191-3.

2. Jones HW. Congenital absence of the pectoral muscles. BMJ. 1926;6:59-60.

3. Lord MJ, Laurenzano KR, Hartmann RW Jr. Poland's syndrome. Clin Pediatr. 1990;29:606-9.

4. Gausewitz SH, Meals RA, Setoguchi Y. Severe limb deficiency in Poland's syndrome. Clin Orthop. 1984;185:9-13.

5. Fraser FC, Teebi A, Walsh S, Pinsky L. Poland sequence with dextrocardia: which comes first? Am J Med Genet. 1997;73:194-6.

6. Eroglu A, Yildiz D, Tunc H. Dextrocardia is a component of left-sided Poland syndrome. J Thorac Cardiovasc Surg. 2005;130:1471-2.

7. Mutlu H, Sildiroglu O, Basekim CC, Kizilkaya E. A variant of Poland syndrome associated with dextroposition. J Thorac Imaging. 2007;22:341-2.
8. Cordero García C, Nieto Castilla A, López Jiménez E, Amores García I. Dextrocardia associated with left-sided Poland syndrome. Am J Phys Med Rehabil. 2009; $88: 168$.

9. Hanks SS, Fox V. Dextrocardia associated with Polands syndrome. J Pediatr. 1975;86:312.

10. Pérez Belmonte E, Ochoa Sangrador C, Marugán Isabel V, Casanueva Pascual T, Carrascal Tejado A. Poland's sequence and dextrocardia. An Pediatr (Barc). 2004;61:350-1.

11. Sepulveda W. Poland syndrome: a rare cause of cardiac dextroposition in the fetus. Prenat Diagn. 2009 [Epub ahead of print].

12. Shamberger R, Welch KJ, Upton J II. Surgical treatment of thoracic deformity in Poland's syndrome. J Pediatr Surg. 1989;24:760-6.

13. Bavinck JNB, Weaver DD. Subclavian artery supply disruption sequence hypothesis of a vascular etiology for Poland, Klippel- Feil, and Mobius anomalies. Am J Med Genet. 1986;23:903-18.

14. Assadi FK, Salem M. Poland syndrome associated with renal agenesis. Paediatr Nephrol. 2003;18:307-8.

15. Al-Qattan MM. Classification of hand anomalies in Poland's syndrome. Br J Plast Surg. 2001;54:132-6.

16. Huang SH, Guo L, Song YZ. Neonatal Poland-Moebius syndrome in a case. Zhonghua Er Ke Za Zhi. 2008;46:718-9.

17. Kiratli H, Erdener U. Poland-Moebius syndrome: a case report. Jpn J Ophthalmol. 2000;44:679-82.

18. Cobben JM, van Essen AJ, McParland PC, Polman HA, ten Kate LP. A boy with Poland anomaly and facio-auriculo-vertebral dysplasia. Clin Genet. 1992;41: 105-7.

19. Guion-Almeida ML, da Silva Lopes VL. Frontonasal dysplasia, Poland anomaly and unilateral hypoplasia of lower limb: report on a male patient. Clin Dysmorphol. 2003;12:233-6.

20. Shalev SA, Hall JG. Poland anomaly-report of an unusual family. Am J Med Genet. 2003;118A:180-3.

21. Happle R. Poland anomaly may be explained as a paradominant trait. Am J Med Genet. 1999;87:364-5.

22. van Steensel MA. Poland anomaly: not unilateral or bilateral but mosaic. Am J Med Genet A. 2004;125A:211-2.

23. Bohun CM, Potts JE, Casey BM, Sandor GGS. A population-based study of cardiac malformations and outcomes associated with dextrocardia. Am J Cardiol. 2007; 100:305-9.

24. Leung AKC, Robson WLM. Dextrocardia with situs solitus. CMAJ. 2006;175: 244.

25. Chen JTT. The chest roentgenogram and cardiac fluoroscopy. In: Alexander RW, Schlant RC, Fuster V, eds. Hurst's the heart. New York: McGraw-Hill; 1995:387-414. 